\title{
Sudden death in a child with epilepsy Potential cerebellar mechanisms?
}

\author{
Fulvio A. Scorza', Vera C. Terra², Ricardo M. Arida ${ }^{3}$, \\ Américo C. Sakamoto ${ }^{2}$, Ronald M. Harper ${ }^{4}$
}

\begin{abstract}
Epilepsy is the most common neurological disorder in humans. People with epilepsy are more likely to die prematurely than those without epilepsy, with the most common epilepsy-related category of death being sudden unexpected death in epilepsy (SUDEP). The central mechanisms underlying the fatal process remain unclear, but cardiac and respiratory mechanisms appear to be involved. Recently, cerebellar, thalamic, basal ganglia and limbic brain structures have been shown to be implicated in respiratory and cardiac rate regulation. We discuss here the potential mechanisms underlying the fatal process, with a description of cerebellar actions likely failing in that SUDEP process.
\end{abstract}

Key words: SUDEP, epilepsy, cerebellum, respiratory mechanisms, seizures.

\section{Morte súbita em uma criança com epilepsia: potenciais mecanismos cerebelares?}

\section{RESUMO}

Epilepsia é uma das doenças neurológicas mais comuns em seres humanos. Pessoas com epilepsia têm maior chance de morrer prematuramente do que pessoas sem epilepsia, sendo a principal causa de óbito a morte súbita em epilepsia (SUDEP). Os mecanismos centrais envolvidos neste processo fatal não são claros, mas mecanismos cardíacos e respiratórios parecem estar envolvidos. Recentemente, regiões cerebrais como o cerebelo, núcleos talâmicos, gânglios basais e estruturas límbicas foram relacionadas com a variação das frequências cardíaca e respiratória. Aqui, discutiremos potenciais mecanismos envolvidos na SUDEP, com uma descrição do possível papel do cerebelo na sua ocorrência.

Palavras-chave: SUDEP, epilepsia, cerebelo, mecanismos respiratórios e crises.

\section{Correspondence}

Fulvio A. Scorza

Rua Botucatu 862

04023-900 São Paulo SP - Brasil

E-mail address: scorza.nexp@epm.br

Conflicts of interest

The authors report no conflict of interest

\section{Support}

FAPESP, CInAPCe-FAPESP, CNPq and INCT/MCT for supporting our studies Ronald M. Harper was supported by $\mathrm{NIH} \mathrm{HD-22695}$

Received 22 February 2011

Received in final form 14 April 2011 Accepted 25 April 2011

\section{Epilepsy and long term evolution}

Epilepsies are one of the most common serious brain disorders, and affects approximately 50 million people worldwide $^{1}$. Almost $25 \%$ of people developing epilepsy evolve with medically intractable epilepsy, with a major proportion of patients in the paediatric group ${ }^{2-4}$. Unfortunately, approximately one in 1000 patients with chronic epilepsy will die suddenly, unexpectedly, and without explanation each year ${ }^{5}$; suden unexpected death in epilepsy (SUDEP) is considered the most important direct epilepsy-related cause of death ${ }^{6}$. A number of associated factors for SUDEP have been assessed, with these factors including: refractoriness of the epileptic condition, presence of generalized tonic-clonic seizures, antiepileptic medication (polytherapy with antiepileptic drugs), duration of the seizure disorder, early onset of epilepsy, and young age $\mathrm{e}^{7,8}$.

Understanding the mechanisms underlying SUDEP may lead to identification of previously-unrecognized risk factors that are more amenable to correction ${ }^{9}$. Although different mechanisms may play separate roles in different cases $^{7}$, the two major domains of potential mechanisms 
of SUDEP are autonomic, i.e., cardiovascular, and respiratory ${ }^{9}$. Pulmonary abnormalities, such as increased lung weight, pulmonary congestion, or edema, consequences of unrestrained autonomic action, appear frequently in postmortem examinations of SUDEP victims ${ }^{9}$. Both central and obstructive apnea can occur during or immediately after a seizure ${ }^{10}$. Obstructive apnea will usually complicate a generalized tonic-clonic seizure, whereas central apnea may occur during both partial and generalized seizures ${ }^{10,11}$. Central hypoventilation and apnoea accompany generalized status epilepticus, and may be an important mechanism in a sheep model of epileptic sudden death ${ }^{12}$. A cardiovascular collapse, either from arrhythmia from the extreme sympathetic activation during a seizure, or from hypotension induced by asystole from profound vagal activation during seizure discharge is also possible.

\section{Brain regions and SUDEP}

Disorders of the central nervous system (CNS) can alter cardiovascular function ${ }^{13}$, and localized brain lesions or dysfunction can modify functional cardiovascular and respiratory alterations. Recognition of these interactions has led to significant advances in understanding the brain sites involved with cardiovascular and respiratory control in adult humans ${ }^{14}$, and many of these sites lie outside classical "respiratory" or "cardiovascular" areas. Several of the sites are limbic regions, which are especially susceptible to seizure discharge, and other sites lie in the cerebellum, a structure ordinarily not considered as mediating breathing control, but now is recognized as a significant respiratory and cardiovascular regulatory site ${ }^{14-20}$. Cerebellar cardiovascular regulatory areas can dampen, i.e., limit extreme changes in hypotension or hypertension to ensure survival. The cerebellum is also responsible for integration of rapid cardiac response to respiratory oscillations ${ }^{18}$, and cerebellar deep nuclei sense $\mathrm{CO}_{2}$ and respond to prolonged apnea ${ }^{16-20}$. Cerebellar roles in compensating for extreme changes in blood pressure or breathing suggests that failure within that structure would enhance the potential for SUDEP.

Of interest, cerebellar abnormalities are quite common in patients with chronic epilepsy, especially when patients are submitted to high doses of antiepileptic drugs, with these patients being at increased risk for SUDEP. Recently, we followed a 9-year-old boy with a history of an uneventful pregnancy, born from a breech delivery with Apgar scores of 5 (first minute) and 8 (fifth minute) and who developed with moderate neurodevelopment delay. Medically-intractable epileptic seizures started at the age of five months. His seizures consisted of daily infantile spasms, and were treated with valproic acid, vigabatrin and predinisone without response. From age 3 to 5 years, he used a ketogenic diet, and was seizure-free. Six months after the ketogenic diet withdrawal (his parents decided not to continue with the regimen), tonic seizures relapsed, with a frequency of one to two weekly. Magnetic resonance imaging revealed diffuse cerebral and cerebellar atrophy. The electroencephalogram consisted of mild brain disorganized activity and rare multifocal spikes. An investigation for metabolic inborn errors was normal. The patient was using phenobarbital (150 mg per day), and died during a prolonged tonic seizure. The patient was in an otherwise good state of health, and post-mortem examination did not reveal any abnormalities. Considering this evidence, the cause of death was considered a SUDEP.

In this patient with poorly controlled epilepsy who died suddenly during a tonic-clonic seizure, loss of respiratory or cardiovascular regulation may be implicated, and may be induced by cerebellar abnormalities unable to perform normal regulatory functions. Several potential processes may have occurred; extreme hypotension or arrhythmia, sustained apneusis, or prolonged apnea, all outcomes in which protective cerebellar compensatory action could have been beneficial if cerebellar structures were not damaged. The precise mechanisms underlying the processes are unclear; however, several pieces of evidence suggest the relationship we propose and the rationale for active pursuit.

A major proportion of patients with epilepsy are pediatric cases (18 years old or less), and approximately $25 \%$ of those patients have medically intractable epilepsy ${ }^{21}$. Only $10-20 \%$ of the children with epilepsy who continue to present with active epilepsy in adulthood will have spontaneous seizure remission, suggesting that early attempts to control the epilepsy should be pursued $^{22-24}$. Epilepsies in the pediatric group may be frequently associated with known potentially risk factors for SUDEP. SUDEP remains a controversial and enigmatic syndrome, particularly in children where the incidence, prevalence and risk factors may differ from adults $^{25}$. Contrary to the widespread opinion that SUDEP does not occur in children, the age of reported cases has ranged from 8 months to 83 years $^{26}$. The incidence of SUDEP in children and adolescents is highly variable, but it is thought to be extremely rare in community-based studies $^{27-29}$. Nevertheless, SUDEP has been identified as being the cause of mortality in $12 \%$ of the children followed over a five-year period time, suggesting that the incidence may not be so rare $^{30}$.

The respiratory changes accompanying increased seizure frequency also suggest SUDEP in this case. This child presented with high seizure frequency (one to two weekly) before death. Most studies that include information on seizure control report a moderate or high 
seizure frequency among SUDEP cases ${ }^{26}$, and SUDEP is considered rare in patients in remission, with only a few such cases reported ${ }^{26}$. Although few data exist about the risk of SUDEP in children, a recent study by our research group demonstrated that increased SUDEP occurrence appeared in children unresponsive to antiepileptic therapy, with no increase in risk observed in patients who remained seizure free ${ }^{31}$.

An additional important issue is evidence that phenytoin can exert toxic effects on the cerebellum in patients with epilepsy ${ }^{32}$; the toxicity is associated with ataxia, tremor, nystagmus and diplopia ${ }^{32,33}$. Furthermore, cerebellar atrophy can occur in phenytoin-exposed patients with epilepsy in the absence of generalised tonicclonic seizures or pre-existent brain damage ${ }^{32,34,35}$. Since the child evaluated in our study did not use phenytoin in his antiepileptic drug therapy schedule, our research group did not consider this issue.

\section{Cerebellar and autonomic process}

The principal evidence for cerebellar involvement was diffuse cerebellar atrophy revealed by magnetic resonance imaging. The evidence for a cerebellar role in breathing is substantial. Chokroverty and colleagues demonstrated a high incidence of obstructive sleep apnea in adults accompanying olivopontocerebellar degenera$\operatorname{tion}^{36}$. Massive intracerebellar hemorrhage (destruction of at least one-third of cerebellar tissue) is frequently accompanied by sudden death during sleep in low-birthweight infants ${ }^{37}$. Cerebellar damage, delayed development $^{38}$, or injury to a principal afferent structure, the olivary nucleus ${ }^{39}$ are all pathological findings reported in the sudden infant death syndrome (SIDS), a sleeprelated syndrome suspected of resulting from a failure of enhanced respiratory efforts to compensate for transient hypotension or an inability to recover from an excessive $\mathrm{CO}_{2}$ challenge ${ }^{14,40,41}$. Similar cerebellar injury was reported in patients with congenital central hypoventilation syndrome, a condition with deficient response to hypercapnia and hypoxia, with possible dysfunction of cerebellar, thalamic, basal ganglia and limbic structures $^{18,41}$. The deep cerebellar nuclei respond to chemosensitive stimuli in both animal ${ }^{16,17}$ and human models ${ }^{18}$. Moreover, the fastigial deep cerebellar nuclei in the cerebellum, when damaged, lead to death following hypotension in animals ${ }^{19}$. The cerebellum, of course, does not act in isolation from its brainstem and other projections in these disrupted actions; compensatory action to recover from extreme hypotension is mediated through cerebellar, vestibular, reticular formation, and ventral medullar blood pressure regulatory nuclei ${ }^{41}$, and chemoreceptor mediation is mediated through medullary afferent and solitary tract nuclei, as well as through re- spiratory motor structures ${ }^{17}$. From this evidence, we suggest that a relationship exists between cerebellar abnormalities and SUDEP.

Cerebellar atrophy is a common finding in people suffering from epilepsy, including temporal lobe epilepsy ${ }^{42-44}$, the most common form of partial epilepsy ${ }^{45}$ and the commonest form of drug-refractory epilepsy ${ }^{42}$. Although the precise mechanisms are still debated, cerebellar volume reduction in people with epilepsy is often attributed to age, presence of generalized tonic-clonic seizures, duration of epilepsy, antiepileptic medication, or the seizure activity itself $\mathrm{f}^{42-44,46,47}$. Specht and colleagues demonstrated in 1997 that cerebellar atrophy diagnosed by MRI was a frequent finding in surgically treated patients with temporal lobe epilepsy ${ }^{44}$, and concluded that increased age, presence of generalized seizures, and intellectual disability were the principal factors associated with cerebellar volume losses in their patients ${ }^{44}$. Botez and co-workers studied 134 adult patients with epilepsy using high-resolution CT scans, and found a higher incidence of cerebellar atrophy with longer duration of epilepsy and treatment with phenytoin ${ }^{48}$. Convincing evidence exists that prolonged phenytoin use, or a single episode of phenytoin intoxication can elicit severe and irreversible cerebellar atrophy $y^{42,44,49,50}$. Although chronic cerebellar stimulation suggests an inhibitory role for the cerebellum as an intervention for intractable seizures, cerebellar volume reduction may reduce these effects in patients with chronic epilepsy $y^{42,44,51}$. Furthermore, cerebellar atrophy, i.e., reductions in hemispheric Purkinje cell density, occurs in epilepsy patients ${ }^{52}$, a finding confirmed by the prominent expression of c-Jun staining of cerebellar Purkinje cells in some SUDEP cases ${ }^{53}$.

The mechanisms underlying cerebellar volume reduction in people with epilepsy may be similar to the processes that result in risk factors for SUDEP. Cerebellar atrophy may lead to an inability to recover from apnea or apneusis, or failure to recover from extreme hypotension or arrhythmia, ultimately resulting in SUDEP in individuals with refractory epilepsy. There are few studies that examine neuropathology with SUDEP; some studies suggest amygdala central nucleus damage may contribute to SUDEP, especially since that structure can play a role in respiratory timing ${ }^{7-11}$.

Despite some progress, SUDEP remains a significant clinical problem. Unfortunately, all the risk factors, mechanisms, and specific methods to prevent SUDEP are yet to be found ${ }^{54}$. Structural, functional and genetic factors are probable involved, and specific brain regions may be directly related. Considering these factors, determination of which brain regions are mainly involved in SUDEP is essential to the understanding of SUDEP mechanisms and prevention. The study of cerebellar 
functioning in patients with epilepsy may be of particularly interest.

The American Epilepsy Society and the Epilepsy Foundation Joint Task Force convened a task force to assess the state of knowledge (research directions, social, cultural and educational efforts) on SUDEP ${ }^{55}$. The potential functional significance of the cerebellum in respiratory and cardiovascular dysfunction in people with chronic epilepsy is that the structure is a brain area with roles for respiratory and cardiovascular regulation, dysfunction of which can compromise life, and these issues represent a specific line of research in the SUDEP field that should be investigated.

\section{REFERENCES}

1. Hauser WA. The prevalence and incidence of convulsive disorders in children. Epilepsia 1994;35(Suppl 2):S1-S6.

2. Nashef L. Sudden unexpected death in epilepsy: terminology and definitions. Epilepsia 1997;38(Suppl):S6-S8.

3. Donner EJ, Smith CR, Snead OC 3rd. Sudden unexplained death in children with epilepsy. Neurology 2001;57:430-434.

4. Baranchuk A, Nault MA, Morillo CA. The central nervous system and sudden cardiac death: what should we know? Cardiol J 2009;16:105-112.

5. Hirsch LJ, Hauser WA. Can sudden unexplained death in epilepsy be prevented? Lancet 2004;364:2157-2158.

6. Duncan JS, Sander JW, Sisodiya SM, Walker MC. Adult epilepsy. Lancet 2006; 367:1087-1100.

7. Surges R, Thijs RD, Tan HL, Sander JW. Sudden unexpected death in epilepsy: risk factors and potential pathomechanisms. Nat Rev Neurol 2009, 5:492-504.

8. Stollberger C, Finsterer J. Cardiorespiratory findings in sudden unexplained/ unexpected death in epilepsy (SUDEP). Epilepsy Res 2004;59:51-60.

9. So EL. What is known about the mechanisms underlying SUDEP? Epilepsia 2008:49:93-98.

10. Ryvlin P, Montavont A, Kahane P. Sudden unexpected death in epilepsy: from mechanisms to prevention. Curr Opin Neurol 2006;19:194-199.

11. Nashef L, Walker F, Allen P, Sander JW, Shorvon SD, Fish R. Apnea and bradycardia during epileptic seizures: relation to sudden death in epilepsy. J Neurol Neurosurg Psychiatry 1996;60:297-300.

12. Johnston SC, Siedenberg R, Min JK, Jerome EH, Laxer KD. Central apnea and acute cardiac ischemia in a sheep model of epileptic sudden death. Ann Neurol 1997:42:588-594.

13. Salo LM, Campos RR, McAllen RM. Differential control of cardiac functions by the brain. Clin Exp Pharmacol Physiol 2006;33:1255-1258.

14. Harper RM, Bandler R, Spriggs D, Alger JR. Lateralized and widespread brain activation during transient blood pressure elevation revealed by magnetic resonance imaging. J Comp Neurol 2000;417:195-204.

15. Harper RM. The cerebellum and respiratory control. Cerebellum 2002;1:1-2

16. Xu F, Zhang Z, Frazier DT. Microinjection of acetazolamide into the fatigial nucleus augments respiratory outoput in the rat. J Appl Physiol 2001;91: 2342-2350.

17. Xu F, Frazier DT. Role of cerebellar deep nuclei in respiratory modulation Cerebellum 2002;1:35-40.

18. Harper RM, Macey PM, Woo MA, et al. Hypercapnic exposure in congenita central hypoventilation syndrome reveals CNS respiratory control mechanisms. J Neurophysiol 2005;93:1647-1658.

19. Lutherer LO, Lutherer BC, Dormer KJ, Janssen HF, Barnes CD. Bilateral lesions of the fastigial nucleus prevent the recovery of blood pressure following hypotension induced by hemorrhage or administration of endotoxin. Brain Res 1983;269:251-257.

20. Yates BJ. Vestibular influences on the autonomic nervous system. In: Highstein SM, Cohen B, Buttner-Ennever JA (Eds). New directions in vestibular research. Ann New York Acad Sci 1996:458-470.

21. Snead III OC. Surgical treatment of medically refractory epilepsy in childhood. Brain Development 2001;23:199-207.

22. Sillanpää M. Epilepsy in children: prevalence, disability, and handicap. Epilepsia 1992;33:444-449.

23. Aicardi J. Risk factors in recurrent seizures and in mental retardation. Rev Neurol 1997:25:754-756.
24. Farmer JP, Montes JL, Freeman CR, Meagher-Villemure K, Bond MC, O'Gorman AM. Brainstem Gliomas: a 10-year institutional review. Pediatr Neurosurg 2001;34:206-214.

25. Appleton RE. Sudden, unexpected death in epilepsy in children. Seizure 1997;6:175-177

26. Tomson T, Walczak T, Sillanpaa M, Sander JW. Sudden unexpected death in epilepsy: a review of incidence and risk factors. Epilepsia 2005;46:54-61.

27. Camfield P, Camfield C. Sudden unexpected death in people with epilepsy: a pediatric perspective. Semin Pediatr Neurol 2005;12:10-14.

28. Sillanpää M, Jalava M, Kaleva O, Shinnar S. Long-term prognosis of seizures with onset in childhood. N Engl J Med 1998;338:1715-1722.

29. Téllez-Zenteno JF, Ronquillo LH, Wiebe S. Sudden unexpected death in epilepsy: evidence-based analysis of incidence and risk factors. Epilepsy Res 2005;65:101-115.

30. Harvey AS, Nolan T, Carlin JB. Community-based study of mortality in children with epilepsy. Epilepsia 1993;34:597-603.

31. Terra VC, Scorza FA, Sakamoto AC, et al. Does sudden unexpected death in children with epilepsy occur more frequently in those with high seizure frequency? Arq Neuropsiquiatr 2009;67:1001-1002.

32. De Marcos FA, Ghizoni E, Kobayashi E, Li LM, Cendes F. Cerebellar volume and long-term use of phenytoin. Seizure 2003;12:312-315.

33. Bruni J. Phenytoin toxicity. In: Levy RH, Mattson RH, Meldrum BS (Eds). Antiepileptic drugs. New York: Raven Press; 1995:345-350.

34. Botez MI, Attig E, Vezina JL. Cerebellar atrophy in epileptic patients. Canad J Neurol Sci 1998;15:299-303.

35. Ney GC, Lantos G, Barr W, Schaul N. Cerebellar atrophy in patients with long-term phenytoin exposure and epilepsy. Arch Neurol 1994;51:767-771.

36. Chokroverty S, Sachdeo R, Masdeu J. Autonomic dysfunction and sleep apnea in olivopontocerebellar degeneration. Arch Neurol 1984;41:926-931.

37. Martin R, Roessmann U, Fanaroff A. Massive intracerebellar hemorrhage in low-birth-weight infants. J Pediatr 1996;89:290-293.

38. Cruz-Sánchez FF, Lucena J, Ascaso C, Tolosa E, Quintò L, Rossi ML. Cerebellar cortex delayed maturation in sudden infant death syndrome. J Neuropathol Exp Neurol 1997;56:340-346.

39. Cortez SC, Kinney HC. Brainstem tegmental necrosis and olivary hypoplasia: a lethal entity associated with congenital apnea. J Neuropathol Exp Neurol 1996;55:841-849.

40. Harper RM, Bandler R. Finding the failure mechanism in the sudden infant death syndrome. Nat Med 1998;4:157-158.

41. Harper RM, Kinney HC, Fleming PJ, Thach BT. Sleep influences on homeostatic functions: implications for sudden infant death syndrome. Respir Physiol 2000;119:123-132.

42. Hagemann G, Lemieux L, Free SL, et al. Cerebellar volumes in newly diagnosed and chronic epilepsy. J Neurol 2002;249:1651-1658.

43. Sandok EK, O'Brien TJ, Jack CR, So EL. Significance of cerebellar atrophy in intractable temporal lobe epilepsy: a quantitative MRI study. Epilepsia 2000;41:1315-1320.

44. Specht U, May T, Schulz R, et al. Cerebellar atrophy and prognosis after temporal lobe resection. J Neurol Neurosurg Psychiatry 1997:62:501-506.

45. Babb TL. Synaptic reorganizations in human and rat hippocampal epilepsy. Adv Neurol 1999;79:763-779.

46. Engel J. Clinical neurophysiology, neuroimaging, and the surgical treatment of epilepsy. Curr Opin Neurol Neurosurg 1993;6:240-249.

47. Lawson JA, Vogrin S, Bleasel AF, Cook MJ, Bye AM. Cerebral and cerebellar volume reduction in children with intractable epilepsy. Epilepsia 2000;41: 1456-1462.

48. Botez MI, Attig E, Vezina JL. Cerebellar atrophy in epileptic patients. Can J Neurol Sci 1998;15:299-303.

49. Masur H, Fahrendorf G, Oberwittler C, Reuther G. Cerebellar atrophy following acute intoxication with phenytoin. Neurology 1990;40:1800-1801.

50. Ney GC, Lantos G, Barr WB, Schaul N. Cerebellar atrophy in patients with long-term phenytoin exposure and epilepsy. Arch Neurol 1994;51:767-771.

51. Davis R, Emmonds SE. Cerebellar stimulation for seizure control: 17-year study. Stereotact Funct Neurosurg 1992;58:200-208.

52. Thom M, Seetah S, Sisodiya S, Koepp M, Scaravilli F. Sudden and unexpected death in epilepsy (SUDEP): evidence of acute neuronal injury using HSP-70 and C-Jun immunohistochemistry. Neuropathol Appl Neurobiol 2003;29:132-143

53. Thom M, Griffin B, Sander JW, Scaravilli F. Amygdala sclerosis in sudden and unexpected death in epilepsy. Epilepsy Res 1999;37:53-62.

54. Lathers CM. Epilepsy and sudden death: personal reflections and call for global action. Epilepsy Behav 2009;15:269-277.

55. So EL, Bainbridge J, Buchhalter JR, et al. Report of the American Epilepsy Society and the Epilepsy Foundation joint task force on sudden unexplained death in epilepsy. Epilepsia 2009;50:917-922. 